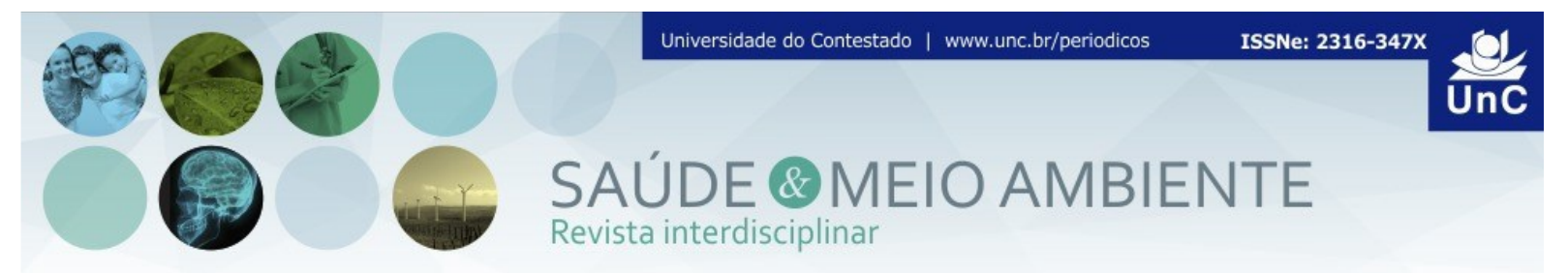

\title{
PROMOÇÃO DO ALEITAMENTO MATERNO NA PREVENÇÃO DE BRONQUITE E BRONQUIOLITE AGUDA EM MENORES DE UM ANO DE IDADE EM RIBEIRÃO PRETO, SÃO PAULO, BRASIL
}

\section{PROMOTION OF BREASTFEEDING TO PREVENT BRONCHITIS AND ACUTE BRONCHIOLITIS IN CHILDREN UNDER ONE YEAR OF AGE IN RIBEIRÃO PRETO, SÃO PAULO, BRAZIL}

\author{
Aline da Mata Pires ${ }^{1}$ \\ Fernanda Cunha Domingos Cruvinel ${ }^{2}$ \\ Karina Salustiano Sousa ${ }^{3}$ \\ Marília Rodrigues Moreira ${ }^{4}$ \\ Stefan Vilges de Oliveira ${ }^{5}$
}

\begin{abstract}
RESUMO
Introdução: A bronquite e a bronquiolite aguda são infecções de vias respiratórias causadas principalmente, pelo vírus sincicial respiratório, que apresenta sua maior incidência em menores de 6 meses. É uma das causas mais frequentes de internação hospitalar em lactentes, sendo um acometimento associado à grande morbidade. Objetivo: Identificar o perfil epidemiológico da bronquite e bronquiolite aguda em menores de 1 ano, na cidade de Ribeirão Preto/SP, e propor estratégias para redução na gravidade dos casos e número de internações. Métodos: Trata-se de um estudo observacional transversal com levantamento de dados sobre bronquite e bronquiolite no Sistema de Informações Hospitalares do SUS, no período de agosto de 2018 a agosto de 2019. Além disso, foi realizada uma revisão sistematizada nas bases de dados: Scielo, Biblioteca Virtual em Saúde (BVS) e PubMed. Resultados: No período avaliado constatou-se um total de 322 internações de menores de 1 ano em Ribeirão Preto, com maior prevalência para o sexo masculino e uma tendência de aumento no tempo e valor médio das internações, o que, consequentemente, gera custos elevados com esse agravo. Discussão: A literatura se baseia no benefício do aleitamento materno para redução da gravidade dos quadros respiratórios e, como resultado, do número de internações desta faixa etária. Conclusão: As intervenções propostas apontam uma necessidade de promoção da amamentação, por meio de campanhas

\footnotetext{
${ }^{1}$ Discente do Curso de Graduação em Medicina da Universidade Federal de Uberlândia, Uberlândia, Minas Gerais, Brasil. E-mail: alinedpires@hotmail.com

2Discente do Curso de Graduação em Medicina da Universidade Federal de Uberlândia, Uberlândia, Minas Gerais, Brasil. E-mail: fernanda.220399@gmail.com

${ }^{3}$ Discente do Curso de Graduação em Medicina da Universidade Federal de Uberlândia, Uberlândia, Minas Gerais, Brasil. E-mail: karinaatletismo9@gmail.com

${ }^{4}$ Docente do Departamento de Saúde Coletiva da Faculdade de Medicina, Universidade Federal de Uberlândia, Uberlândia, Minas Gerais, Brasil. E-mail: marilia.moreira@ig.com.br

${ }^{5}$ Docente do Departamento de Saúde Coletiva da Faculdade de Medicina, Universidade Federal de Uberlândia, Uberlândia, Minas Gerais, Brasil. E-mail: stefanbio@yahoo.com.br
} 
escolares, capacitação dos profissionais de saúde e conscientização das famílias para reverter e/ou pelo menos melhorar a situação atual.

Palavras chaves: Bronquiolite. Aleitamento Materno. Doenças Respiratórias. Promoção da Saúde.

\begin{abstract}
Introduction: The Bronchitis and Acute Bronchiolitis are respiratory tract infections caused by the respiratory syncytial virus that has highest incidence in children younger than 6 months old. It is one of the most common causes of hospitalization in infants, being associated with high morbidity levels. Objective: Identify the epidemiological profile of Bronchitis and Acute Bronchiolitis in children younger than 1 year old, in the city of Ribeirão Preto, in São Paulo, and present strategies for decreasing the gravity of the cases and number of hospitalizations. Methods: This is a descriptive ecological study based on collecting data about Bronchitis and Bronchiolitis in the Hospital Information System of SUS, in the period between august 2018 to august 2019. It was also done a systematic review in the according databases: Scielo, Virtual Health Library (VHL) and PubMed. Results: It was observed a total of 322 hospitalizations in children younger than 1 year, in the analysed period, in Ribeirão Preto, and it was noted a higher prevalence in males. Beyond that, it was observed a rising tendency of the time and average value of the hospitalizations, leading to a higher expense with this grievance. Discussion: The literature is based on the benefit of breastfeeding for reducing the gravity of the respiratory distress, and, consequently, the number of hospitalizations in this age group. Conclusion: The proposed interventions lead to a necessity of promoting breastfeeding, through school campaigns, professional capacitation of healthcare providers and raising awareness of families to reverse the current situation.
\end{abstract}

Key Words: Bronchiolitis. Breast Feeding. Respiratory Tract Diseases. Health Promotion.

\title{
INTRODUÇÃO
}

A bronquiolite viral aguda (BVA) é uma infecção do trato respiratório inferior, resultado da obstrução inflamatória das pequenas vias aéreas. Nas crianças de pouca idade é a infecção do trato respiratório inferior mais comum ${ }^{(1)}$. O principal agente etiológico é o Vírus Sincicial Respiratório (VSR). As infecções pelo VSR não conferem imunidade completa, sendo comuns as reinfecções durante a vida(2). Além do VSR, outros agentes também causam a BVA, como influenza, rinovírus, parainfluenza (tipos 1 e 3), adenovírus, metapneumovírus, bocavírus humano, entre outros ${ }^{(2)}$.

Depois da incubação (4 a 6 dias) a criança desenvolve sintomas das vias respiratórias superiores, que depois se dissemina para as vias respiratórias baixas. $\mathrm{O}$ 
quadro clínico inicial inclui rinorreia, tosse e febre baixa, que evolui para dificuldade respiratória associada a sinais de obstrução brônquica e sibilância(1).

Segundo a Sociedade Brasileira de Pediatria, a doença é autolimitada, sendo mais frequente durante os primeiros 2 anos, com uma incidência maior nos menores de 6 meses de idade ${ }^{(3)}$. É uma das causas mais frequentes de internação hospitalar nessa faixa etária e é reconhecida como uma enfermidade associada à grande morbidade(1). Até os 2 anos de idade praticamente todas as crianças já terão sido infectadas por um dos agentes etiológicos da BVA, desenvolvendo ou não a doença. As formas graves ocorrem em bebês de baixa idade, entre 1 e 3 meses de vida. São fatores de risco para infecções das vias aéreas inferiores e associadas com BVA: baixo peso ao nascimento, desnutrição, idade materna, amamentação e aglomeração(2).

Segundo dados da Organização Pan-americana da Saúde (OPAS) e da Organização Mundial de Saúde (OMS) 40 a $60 \%$ de todos os atendimentos ambulatoriais em pediatria referem-se a infecções respiratórias agudas na América Latina. Segundo a OMS, cerca de 4 milhões de crianças menores de 5 anos morrem por infecções agudas das vias aéreas inferiores (IVAI) anualmente. Além disso, essas doenças geram elevados custos diretos e indiretos com assistência à saúde. Dentre os vários agentes etiológicos causadores de IVAI, os vírus são responsáveis por bronquiolite e pneumonia, principalmente em crianças menores de 1 ano ${ }^{(4)}$. No mundo, a incidência da BVA é de $11 \%$ até 1 ano de idade e de $6 \%$ até os 2 anos. O pico de incidência ocorre entre 2 e 5 meses de idade. Nas crianças menores de 1 ano, o risco de hospitalização pela doença é de aproximadamente $2 \%{ }^{(2)}$.

O diagnóstico é essencialmente clínico-radiológico e sendo assim, há alguma dificuldade em firmar um conhecimento exato da distribuição da doença na população. A mortalidade das crianças hospitalizadas por BVA varia de $1 \%$ a 3,5\% e as infecções bacterianas secundárias podem aumentar a morbidade e a mortalidade por BVA ${ }^{(5)}$. As complicações agudas estão relacionadas às pneumopatias decorrentes de hiperinsuflação pulmonar e ocorrem em $79 \%$ das crianças. $60 \%$ das crianças apresentam complicações respiratórias, 41\% infecções e 9\% complicações cardiovasculares ${ }^{(5)}$.

Para a diminuição do número de casos indica-se a prevenção, que pode ser feita com medidas simples, mas eficazes, como evitar o contato com crianças e adultos resfriados, lavar as mãos e higienizá-las com álcool 70\%, principalmente antes de tocar os bebês, além de fugir de aglomerações e evitar o tabagismo passivo(6). Uma outra medida de extrema importância é a promoção da amamentação. Vários estudos, no Brasil e no mundo, demonstram a relação entre o aleitamento materno e as infecções respiratórias ${ }^{(7)}$.

Com base no exposto, este trabalho objetiva analisar o perfil epidemiológico dos casos de BVA na cidade de Ribeirão Preto/SP e a partir de achados bibliográficos de maior relevância, propor intervenções com vistas a uma redução do número de casos e, consequentemente, de internações hospitalares por BVA. 


\section{MATERIAL E MÉTODOS}

A cidade de Ribeirão Preto está localizada no estado de São Paulo e segundo a última estimativa realizada pelo IBGE é uma cidade de 703.293 habitantes, com uma população predominantemente de jovens adultos. A cidade possui um Produto Interno Bruto (PIB) per capita de mais de $\mathrm{R} \$ 44.400,00$, sendo assim uma das mais ricas do estado, e a mais rica da microrregião ${ }^{(8)}$.

No âmbito da saúde, a cidade conta com 319 estabelecimentos, sendo que somando há 33 Unidades Básicas e Distritais de Saúde (UBDS) e Unidades Básicas de Saúde (UBS), além de outras unidades da atenção primária como CAPS e centros de reabilitação. Além disso, o município conta ainda com diversos programas em saúde, que possuem diversos temas como Saúde da Mulher, Saúde da Criança e do Adolescente, Imunização, Aleitamento Materno, Nutrição, Núcleo de Atenção ao Deficiente, entre outros ${ }^{(8)}$.

Para analisar o perfil epidemiológico de internações por bronquite e bronquiolite viral aguda da cidade foi realizado um estudo epidemiológico descritivo transversal com um levantamento de dados no Sistema de Informações Hospitalares do SUS SIH/DATASUS no período de agosto de 2018 a agosto de 2019(9). Após delimitar o contexto da BVA e identificar a idade de maior incidência da doença e o sexo de maior prevalência, levantou-se dados para verificar o número de internações e os custos delas para essa comorbidade, assim como o tempo médio de internação na faixa etária predominante da doença.

A revisão da literatura consultada para o levantamento de dados necessária para o desenvolvimento desse projeto foi feita através das bases de dados Scielo, Biblioteca Virtual em Saúde (BVS) e PubMed, com os seguintes descritores: "Bronquiolite", "Aleitamento", "Promoção", "Intervenção" e "Doenças Respiratórias" buscando por textos publicados entre os anos de 2009 e 2019.

Foram utilizados como critério de exclusão a não relação do título e resumo dos textos com o tema de bronquiolite e/ou aleitamento materno, a não relação deles com a prevenção de infecções respiratórias, especialmente BVA, a inexistência de intervenções para a promoção do aleitamento ou a não relação deles com a epidemiologia de BVA. Foram incluídos os trabalhos com presença de elementos referentes a uma intervenção em saúde para promoção do aleitamento materno realizada com sua descrição, seu desenvolvimento, seus resultados e/ou a comparação entre diferentes intervenções. Além da busca sistematizada foram incluídos textos de literatura cinzenta do Ministério da Saúde e dados do site da Secretaria de Saúde de Ribeirão Preto. 


\section{RESULTADOS}

O levantamento de dados realizado no SIH/DATASUS referentes ao período de agosto de 2018 a agosto de 2019, demonstrou que houveram 322 internações em crianças menores de 1 ano por BVA na cidade de Ribeirão Preto (Tabela 1). Desse total de internações, observou-se que o sexo masculino foi responsável pela maioria dos casos $(64,6 \%)$, quando comparado ao sexo feminino $(35,4 \%)$.

Tabela 1 - Número total de internações, tempo total e médio de permanência na internação e valor total e médio de internação, de menores de 1 ano por bronquite e BVA, entre agosto de 2018 e agosto de 2019 em Ribeirão Preto.

\begin{tabular}{llllll}
\hline Município & $\begin{array}{l}\text { Número de } \\
\text { internações }\end{array}$ & $\begin{array}{l}\text { Dias totais de } \\
\text { permanência }\end{array}$ & $\begin{array}{l}\text { Média dias de } \\
\text { permanência }\end{array}$ & $\begin{array}{l}\text { Valor total } \\
\text { (reais) }\end{array}$ & $\begin{array}{l}\text { Valor médio } \\
\text { (reais) }\end{array}$ \\
\hline Ribeirão Preto & 322 & 1.494 & 4,6 & $271.078,20$ & 841,86
\end{tabular}

Fonte: Brasil. Ministério da Saúde - Sistema de Informações Hospitalares do SUS (SIH/SUS)

Foi possível notar, também, pelo Gráfico 1, que as internações são mais frequentes entre os meses de Junho (38) e Julho (35), além de observar-se uma queda de metade do número de casos de Agosto de 2018 (32) para Agosto de 2019 (16).

Examinando o tempo total de internação por mês demonstrado no Gráfico 2, nota-se que o mês de Agosto de 2018 teve o maior número de dias de internação, com um total de 171 dias, seguido pelo mês de Julho de 2019 (155). O mês com o menor número de dias de internação foi Dezembro de 2018, que teve 60 dias totais apenas.

Gráfico 1 - Número de internações por mês, de menores de 1 ano, por Bronquite e Bronquiolite Viral Aguda, entre agosto de 2018 e agosto de 2019 em Ribeirão Preto

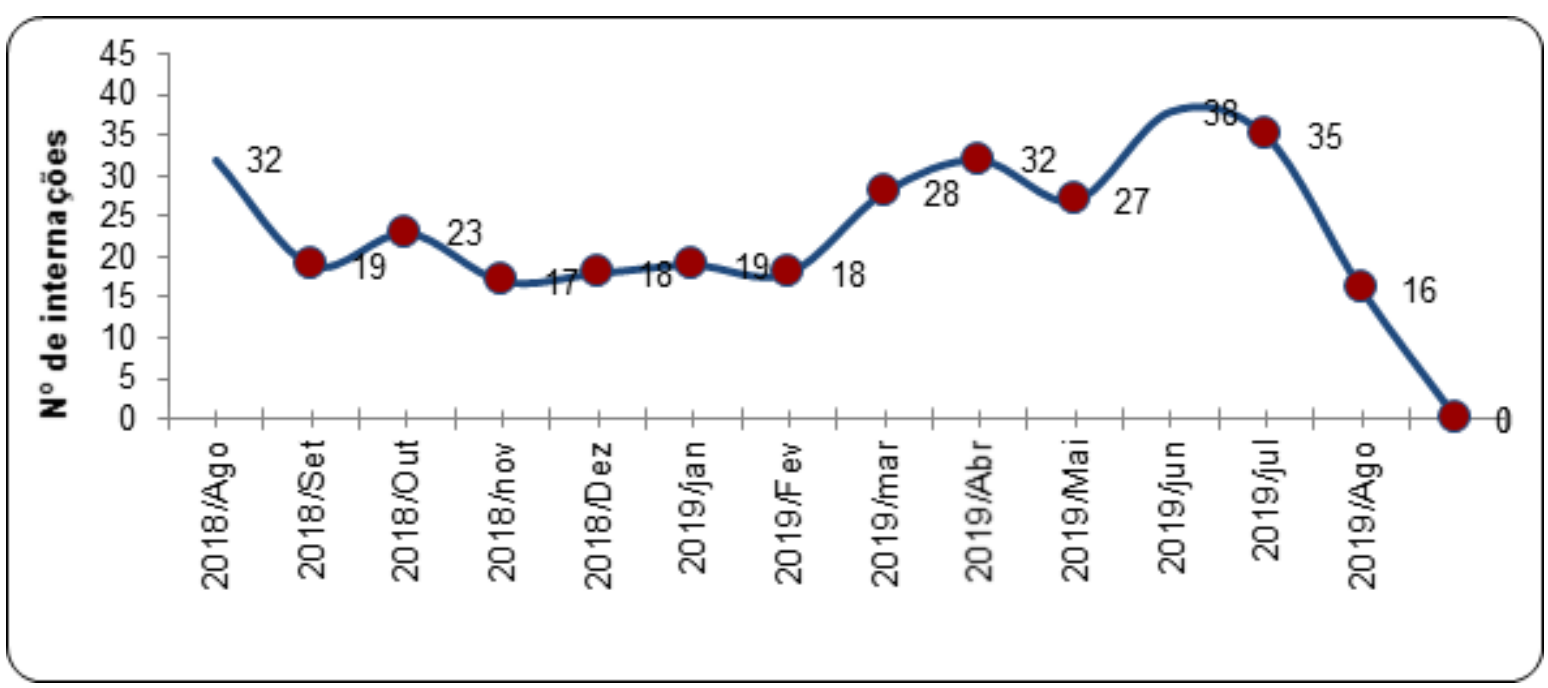

Fonte: Brasil. Ministério da Saúde - Sistema de Informações Hospitalares do SUS (SIH/SUS) 
Gráfico 2 - Tempo total de permanência e valor total de internação, por mês, de menores de 1 ano por bronquite e BVA, entre agosto de 2018 e agosto de 2019 em Ribeirão Preto

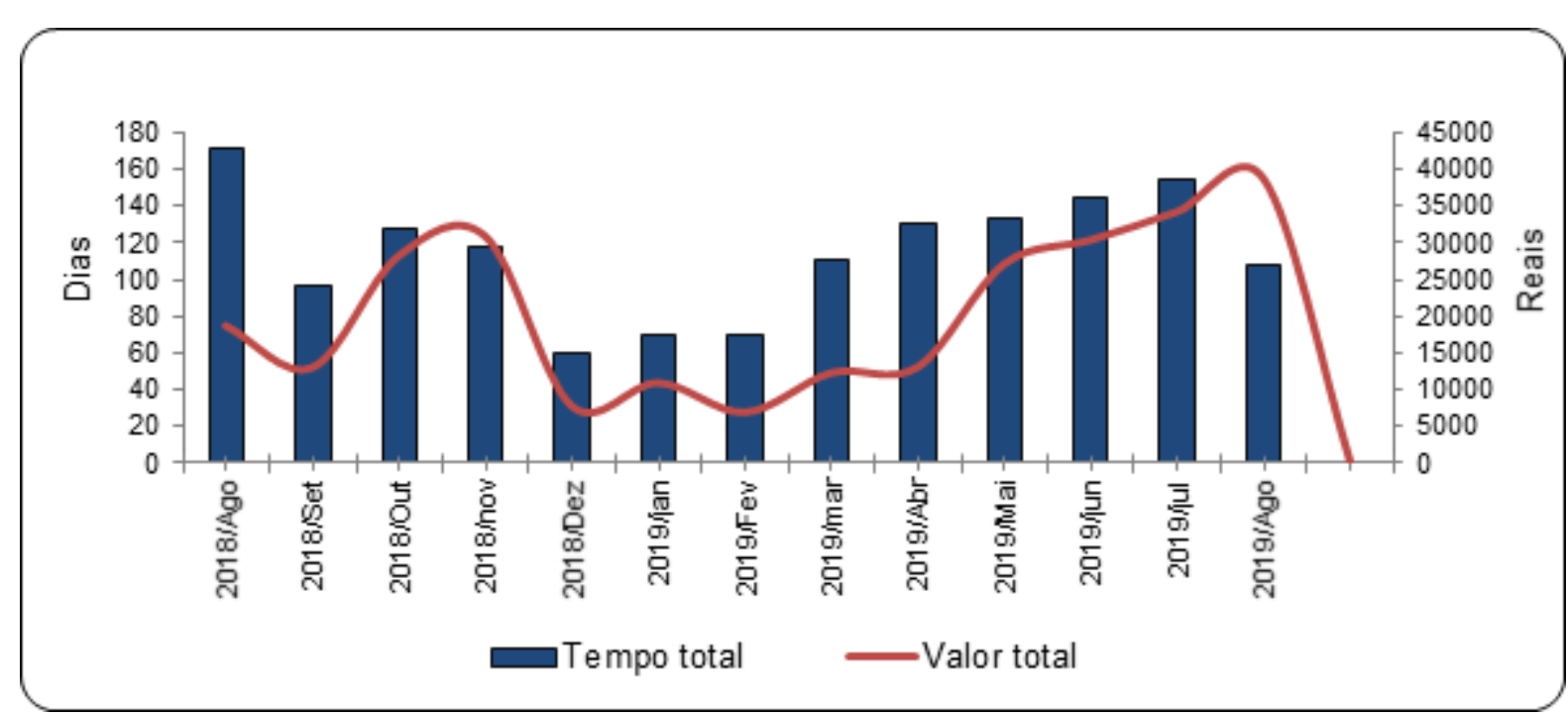

Fonte: Brasil. Ministério da Saúde - Sistema de Informações Hospitalares do SUS (SIH/SUS)

Em relação à média de dias por internação, o Gráfico 3 demonstra que o mês em que as internações duravam mais tempo foi Novembro de $2018(6,9)$, e em segundo lugar Agosto de 2019 (6,8). O mês que teve o menor número de dias por internação foi Dezembro de 2018 (3.3).

Gráfico 3 - Tempo médio de permanência e valor médio por internação por mês, de menores de 1 ano por bronquite e BVA, entre agosto de 2018 e agosto de 2019 em Ribeirão Preto

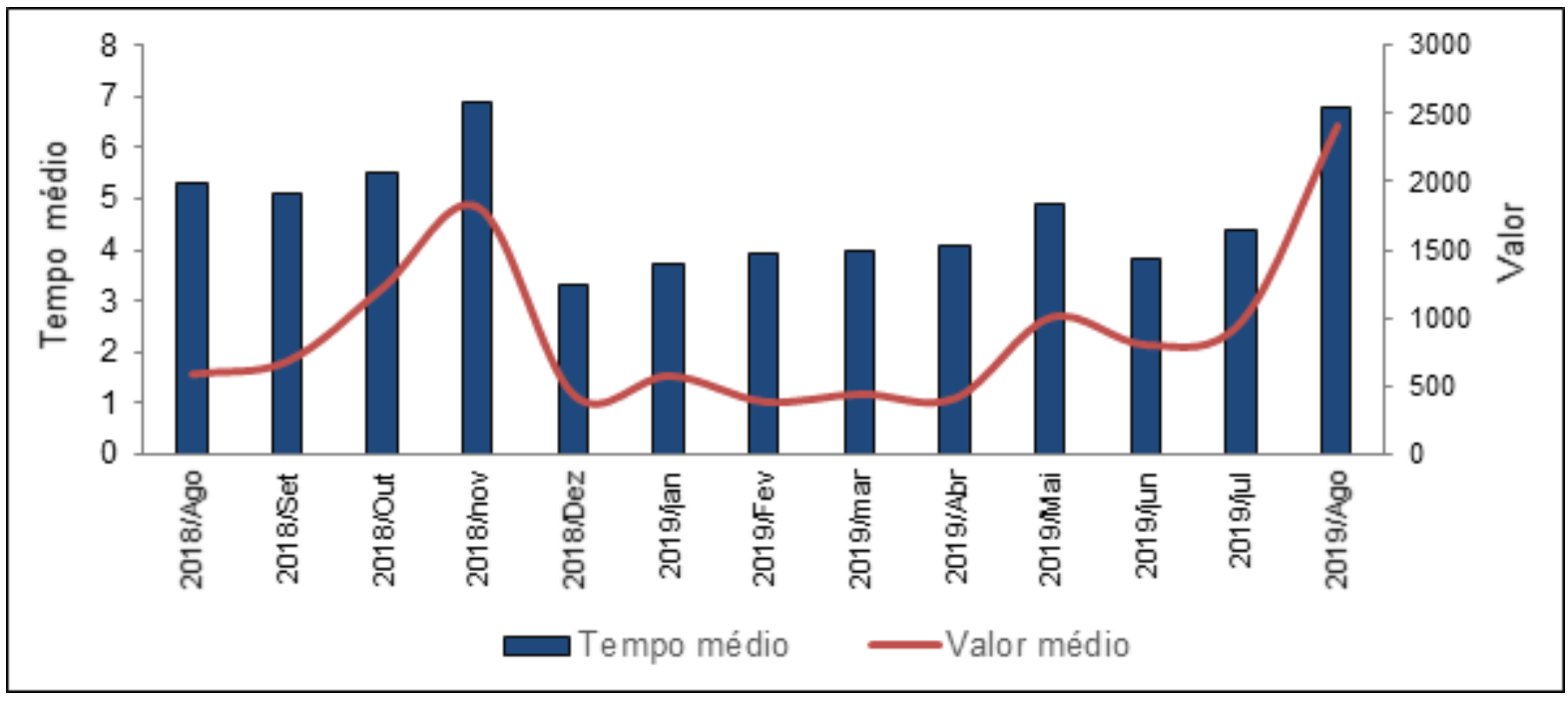

Fonte: Brasil. Ministério da Saúde - Sistema de Informações Hospitalares do SUS (SIH/SUS) 
A última variável analisada foi o valor total e médio das internações. Conforme a Tabela 1, o valor total gasto com internações, no período, foi de $271.078,20$ reais, sendo que cada internação custou uma média de 841,86 reais.

Observa-se pelo Gráfico 2 que os meses com maior número de gastos totais foram Julho e Agosto de 2019, com 34.162,77 e 38.615,21 reais, respectivamente. O mês de Agosto de 2019 também foi responsável pela maior média de gastos por internação, chegando cada internação ao preço de $2.413,45$ reais, como representado no Gráfico 3. Por fim, identifica-se nos dois gráficos citados, que o mês de Fevereiro de 2019 teve o menor custo total e médio de internação, sendo estimado $6.813,95$ reais totais e 378,55 reais médios.

Após a revisão da literatura, embora o número de artigos que se adequassem ao tema fosse restrito, foi observada uma predominância de intervenções voltadas à prevenção da bronquite e BVA, por meio de estratégias simples, como higienização das mãos e evitar aglomerações e contato com pessoas resfriadas ${ }^{(5)}$, além de promoção do aleitamento, que evita vários tipos de infecções e comorbidades ${ }^{(9)}$. No Quadro 1 estão representadas as principais propostas encontradas. A partir de tais resultados foi possível estruturar a presente proposta de intervenção.

Quadro 1 - Propostas de intervenção para a redução do número de internações por Bronquiolite viral aguda segundo a revisão bibliográfica sistematizada

\begin{tabular}{|c|c|c|c|}
\hline $\begin{array}{l}\text { Proposta de } \\
\text { Intervenção }\end{array}$ & $\begin{array}{l}\text { Recursos } \\
\text { Necessários }\end{array}$ & $\begin{array}{l}\text { Resultados } \\
\text { Esperados }\end{array}$ & $\begin{array}{l}\text { Referência } \\
\text { Bibliográfica }\end{array}$ \\
\hline $\begin{array}{l}\text { Capacitação de médicos } \\
\text { da família e/ou obstetras } \\
\text { para orientarem sobre } \\
\text { amamentação no pré- } \\
\text { natal. }\end{array}$ & $\begin{array}{l}\text { Recursos financeiros } \\
\text { e humanos para } \\
\text { capacitação de } \\
\text { médicos da família e } \\
\text { obstetras. }\end{array}$ & $\begin{array}{l}\text { Aumento da } \\
\text { amamentação e, } \\
\text { consequente, redução } \\
\text { do número de } \\
\text { internações por } \\
\text { Bronquite e } \\
\text { Bronquiolite Aguda }\end{array}$ & Stephan et al., (15) \\
\hline $\begin{array}{l}\text { Promoção da } \\
\text { amamentação por } \\
\text { pediatras e outros } \\
\text { profissionais envolvidos } \\
\text { no cuidado à saúde da } \\
\text { criança }\end{array}$ & $\begin{array}{l}\text { Recursos humanos e } \\
\text { financeiros para } \\
\text { capacitação e } \\
\text { conscientização dos } \\
\text { profissionais. }\end{array}$ & $\begin{array}{l}\text { Elevação das taxas } \\
\text { de aleitamento } \\
\text { materno e redução na } \\
\text { gravidade dos } \\
\text { quadros de Bronquite } \\
\text { e Bronquiolite Aguda }\end{array}$ & Santiago et al., (17) \\
\hline $\begin{array}{l}\text { Projetos nas escolas } \\
\text { sobre a amamentação. }\end{array}$ & $\begin{array}{l}\text { Recursos humanos e } \\
\text { financeiros para } \\
\text { ocorrer a educação } \\
\text { em saúde sobre } \\
\text { amamentação nas } \\
\text { escolas. }\end{array}$ & $\begin{array}{l}\text { Formação e } \\
\text { disseminação de } \\
\text { conhecimentos e } \\
\text { atitudes positivas no } \\
\text { que se refere à } \\
\text { amamentação, com } \\
\text { consequente aumento } \\
\text { do aleitamento } \\
\text { materno e diminuição } \\
\text { das internações por } \\
\text { bronquite e BVA }\end{array}$ & Montrone et al., (18) \\
\hline
\end{tabular}


Promoção do aleitamento materno na prevenção de bronquite e bronquiolite aguda em menores de um ano de idade em Ribeirão Preto, São Paulo, Brasil

\begin{tabular}{|l|l|l|l|}
\hline $\begin{array}{l}\text { Aplicativos móveis sobre } \\
\text { o aleitamento materno }\end{array}$ & $\begin{array}{l}\text { Recursos humanos e } \\
\text { financeiros para o } \\
\text { desenvolvimento de } \\
\text { aplicativos sobre } \\
\text { aleitamento e } \\
\text { atualização de suas } \\
\text { informações. }\end{array}$ & $\begin{array}{l}\text { Disseminação da } \\
\text { informação sobre } \\
\text { amamentação a } \\
\text { lugares remotos, } \\
\text { aumentando o } \\
\text { aleitamento materno. }\end{array}$ & Diniz et al., (19) \\
\hline $\begin{array}{l}\text { Intervenção telefônica na na } \\
\text { promoça da } \\
\text { amamentação }\end{array}$ & $\begin{array}{l}\text { Recursos humanos e } \\
\text { financeiros para a } \\
\text { realização das } \\
\text { ligações telefônicas e } \\
\text { capacitação de } \\
\text { profissionais de } \\
\text { saúde. }\end{array}$ & $\begin{array}{l}\text { Manutenção do } \\
\text { aleitamento materno. }\end{array}$ & Chaves et al., (20) \\
\hline
\end{tabular}

\section{DISCUSSÃO}

A partir dos dados coletados no SIH/DATASUS e representados nos gráficos, na cidade de Ribeirão Preto há um número importante de internações por Bronquite e BVA em crianças menores de 1 ano de idade, e percebe-se uma tendência de aumento nos gastos com essas internações nos últimos meses.

Ao observar os meses de maior frequência de internações (junho e julho), percebe-se que é compatível com a literatura, que diz ocorrer epidemicamente nos meses de outono e inverno ${ }^{(10,11)}$, que vai de março a setembro no Brasil. No verão, houve menor número de internações (dezembro e janeiro).

Outro dado que condiz com a literatura é a predominância de meninos em relação às meninas. Na cidade estudada, $64,6 \%$ dos meninos foram responsáveis pelas internações por Bronquiolite Aguda. De acordo com estudo de Alvarez et al., dos 12.474 lactentes com BVA, 1588 foram internados e o risco de internação era maior nos pacientes do sexo masculino ${ }^{(12)}$.

Analisando os dados coletados, observa-se uma discrepância entre Ribeirão Preto e outras cidades com um número de habitantes semelhante. Comparando com a cidade de Uberlândia (MG), verifica-se que Ribeirão, no mesmo período, apresentou um número muito maior de internações por Bronquite e Bronquiolite Aguda, sendo que em Uberlândia foram 60 internações e em Ribeirão Preto $322^{(10)}$.

Infere-se que o importante número de internações tem relação com o percentual de amamentação. Segundo a Pesquisa de Prevalência de Aleitamento Materno em Municípios Brasileiros em Ribeirão Preto, o aleitamento materno exclusivo até os 6 meses de idade foi de $40,76 \%$. Comparando com a cidade de Uberlândia, encontra-se um percentual de $43,52 \%$. Ainda, na mesma pesquisa, o percentual de amamentação dos 9 aos 12 meses de idade foi de $45,26 \%$ na cidade paulistana, contra os $53,47 \%$ da cidade mineira. Tais números sugerem que um maior 
percentual de amamentação no primeiro ano de vida está relacionado a um menor número de internações por Bronquite e Bronquiolite Aguda(10).

Vários estudos em todo o mundo, inclusive no Brasil, demonstram a proteção que o aleitamento proporciona contra infecções respiratórias. A proteção é maior quando a amamentação é exclusiva nos primeiros seis meses de vida. $\mathrm{O}$ aleitamento materno diminui a gravidade dos episódios de infecção respiratória e tem um efeito protetor contra a mortalidade infantil (7). Em Pelotas (RS), as crianças amamentadas por menos de um mês apresentaram 7,7 vezes mais chance de hospitalização por bronquiolite viral aguda(13)

A amamentação exerce efeito protetor não só no que se refere às infecções respiratórias, especialmente na Bronquiolite Aguda, mas também evita diarreia e exerce efeito em sua gravidade, diminui o risco de alergias (como alergia à proteína do leite de vaca, dermatite atópica, além de asma e sibilos), diminui o risco de hipertensão, hipercolesterolemia e diabetes, reduz a chance de obesidade e diminui a mortalidade infantil ${ }^{(7)}$.

Além do número de internações em Uberlândia serem menores que em Ribeirão Preto, os gastos com esse agravo são significativamente reduzidos na cidade de Minas Gerais. O valor total despendido em Ribeirão Preto é de 271.078,20 reais, sendo que cada paciente requer aproximadamente 841,86 reais em seu tratamento. Em contrapartida, em Uberlândia os gastos totais chegam a 37.116,92 reais, praticamente 7 vezes menos que a cidade paulista, e o custo individual de tratamento é cerca de 200 reais mais barato $(618,68 \text { reais })^{(9)}$.

Diante de todo esse contexto, propõe-se o desenvolvimento de estratégias para promoção do aleitamento materno, principalmente no primeiro ano de vida. Assim, em nível primário, médicos da família e/ou obstetras devem favorecer a amamentação a partir de orientações no período pré-natal acerca de cuidados com as mamas, técnicas de amamentação, informação sobre vantagens da amamentação, incentivo à livre demanda e sobre o não uso de chupetas, mamadeira e outros leites ${ }^{(14)}$.

Dessa forma, as equipes de profissionais atuantes na Estratégia Saúde da Família (ESF), devem estar capacitados para acolher a gestante de forma precoce, garantindo informações adequadas para a mãe, a criança, a família e a comunidade como um todo ${ }^{(15)}$. Essa capacitação pode ser feita por meio de treinamento teóricoprático da Iniciativa Hospital Amigo da Criança, que foi lançada pela Organização Mundial da Saúde (OMS) e pelo Fundo das Nações Unidas para a Infância (UNICEF), com o objetivo de promover e apoiar o aleitamento materno no âmbito hospitalar ${ }^{(16)}$.

Além disso, o pediatra tem papel fundamental na promoção da amamentação, por sua importância, pois ocupa posição de referência para o núcleo familiar no que se refere à saúde no SUS. Por isso, ele deve sempre procurar treinamento específico para orientações sobre aleitamento materno exclusivo. Verifica-se que o pediatra que motiva a amamentação obtém resultados positivos em relação às taxas de aleitamento $^{(17)}$.

Também, nota-se a importância de projetos nas escolas. Um projeto para a promoção da amamentação foi realizado com 38 crianças de Ensino fundamental de 
uma escola em São Carlos, por meio de jogos, brincadeiras, rodas de conversa e músicas para promover o aleitamento, envolvendo crianças, professores $\mathrm{e}$ funcionários. Como resultado, observou-se que tal projeto contribuiu para formar e disseminar conhecimentos e atitudes positivas no que se refere à amamentação(18).

Ainda, as tecnologias digitais têm grande contribuição para o aleitamento materno. $\mathrm{O}$ crescimento das tecnologias e o grande número de pessoas que possuem aparelhos móveis corroboram essa importância. Assim, por meio de aplicativos móveis, há a disseminação da informação sobre amamentação a lugares remotos, alcançando grande parte da população, em especial, as gestantes, as puérperas e os familiares dessas mulheres, mostrando a importância do tema e aumentando o aleitamento materno ${ }^{(19)}$.

Por fim, observa-se a importância da intervenção telefônica na promoção da amamentação. A intervenção é eficaz para manter o aleitamento materno, tanto em curto como em longo prazo, pois o mantém aos dois e quatro meses. Além disso, o apoio telefônico profissional eleva a auto eficácia em amamentar ${ }^{(20)}$.

\section{CONCLUSÃO}

Neste estudo, o perfil encontrado para os casos de Bronquite e Bronquiolite Aguda foi semelhante aos disponíveis na literatura no que se refere às épocas do ano de maior ocorrência e à maior prevalência no sexo masculino. Além disso, infere-se uma relação entre os casos dessa comorbidade com o aleitamento materno.

Os dados apontam uma necessidade de promoção da amamentação, por meio de incentivo na atenção primária por médicos da família e/ou obstetras no pré-natal, pediatras durante as consultas ambulatoriais ou outros profissionais envolvidos no cuidado à saúde da criança, além de ações nas escolas para disseminar a importância da amamentação no núcleo familiar e na sociedade como um todo, além do desenvolvimento de aplicativos móveis e da realização de intervenção telefônica para promover o aleitamento materno.

\section{REFERÊNCIAS}

1. Zorc JJ, Hall CB. Bronchiolitis: recent evidence on diagnosis and management. J. Pediatr 2010 Feb; 125(2):342-9.

2. Ralston SL, Lieberthal AS, Meissner HC, Alverson BK, Baley JE, Gadomski AM. Clinical practice guideline: the diagnosis, management, and prevention of bronchiolitis. J Pediatr 2014;134(5):1474-1502. 
3. Sociedade Brasileira de Pediatria. Departamentos Científicos de Cardiologia, Imunizações, Infectologia, Neonatologia e Pneumologia. Diretrizes para o manejo da infecção causada pelo Vírus Sincicial Respiratório (VSR); 2017.

4. Júnior JBS, Gardinassi LGA, Simas PMV, Bittar CO, Souza, FP, Rahal P, Zanetta DMT. Vírus respiratório sincicial humano em crianças hospitalizadas por infecções agudas das vias aéreas inferiores. J Pediatr (Rio J). 2011;87(3):219-224.

5. Amantéa SL. Bronquiolite Viral Aguda. In: Burns DAR, Júnior DC, Silva LR, Borges WG, Blank D. Tratado de Pediatria: Sociedade Brasileira de Pediatria. 4. ed. Barueri, SP: Manole; 2017. p. 1720-29.

6. UpToDate [homepage na internet]. Bronchiolitis in infants and children: Treatment, outcome, and prevention [acesso em 20 nov 2019]. Disponível em: http://www.uptodate.com/online

7. Brasil. Ministério da Saúde. Secretaria de Atenção à Saúde. Departamento de Atenção Básica. Saúde da criança: aleitamento materno e alimentação complementar. Cadernos de Atenção Básica. 2. ed. Brasília: MS; 2015.

8. Instituto Brasileiro de Geografia e Estatística [homepage na internet]. Panorama de Ribeirão Preto [acesso em 01 dez 2019]. Disponível em: https://cidades.ibge.gov.br/

9. Ministério da Saúde. Datasus [homepage na internet]. Sistema de Informações Hospitalares do SUS [Acesso em 12 out 2019]. Disponível em: http://datasus.saude.gov.br/

10. Brasil. Ministério da Saúde. Secretaria de Atenção à Saúde. Departamento de Ações Programáticas e Estratégicas. Pesquisa de Prevalência de Aleitamento Materno Em Municípios Brasileiros. Brasília: MS; 2010.

11. Carvalho WB, Johnston C, Fonseca MC. Bronquiolite aguda, uma revisão atualizada. Rev Assoc Med Bras 2007;53(2):182-8.

12. Alvarez AE, Marson FA, Bertuzzo CS, Arns CW, Ribeiro JD. Epidemiological and genetic characteristics associated with the severity of acute viral bronchiolitis by respiratory syncytial virus. J Pediatr 2013;89(6):531-543.

13. Albernaz EP, Menezes AM, Cesar JA. Fatores de risco associados à hospitalização por bronquiolite aguda no período pós-natal. Rev. Saúde Pública 2003;37(4):485-93.

14. Nascimento VC, Oliveira MIC, Alves VH, Silva KS. Associação entre as orientações pré-natais em aleitamento materno e a satisfação com o apoio para amamentar. Rev. Bras Saúde Matern Infant 2013;13(2):147-59. 
15. Stephan AMS, Cavada MN, Vilela CZ. Prevalência de aleitamento materno exclusivo até a idade de seis meses e características maternas associadas, em área de abrangência de unidade de Saúde da Família no município de Pelotas, estado do Rio Grande do Sul, Brasil, 2010. Epidemiol Serv Saúde 2012; 21(3).

16. Jesus PC, Oliveira MIC, Moraes JR. Capacitação de profissionais de saúde em aleitamento materno e sua associação com conhecimentos, habilidades e práticas. Ciênc. Saúde Coletiva 2017;22(1):311-20.

17. Santiago LB, Bettiol H, Barbieri MA, Gutierrez MRP, Ciampo LAD. Incentivo ao aleitamento materno: a importância do pediatra com treinamento específico. J Pediatr 2003;79(6).

18. Montrone AVG, Arantes CIS, Lébeis NM, Pereira TACF. Promoção da amamentação por crianças do Ensino Fundamental. Interface - Comunicação, Saúde, Educação 2009;13(31):449-59.

19. Diniz CMM, Leal LP, Guedes TG, Linhares FMP, Pontes CM. Aportes de las aplicaciones móviles para la práctica de la lactancia materna: revisión integradora. Acta Paul Enferm 2019;32(5).

20. Chaves AFL, Ximenes LB, Rodrigues DP, Vasconcelos, CTM, Monteiro JCS, Oriá MOB. Intervenção telefônica na promoção da autoeficácia, duração e exclusividade do aleitamento materno: estudo experimental randomizado controlado. Rev Latino-Am Enf 2019;27(0):1-9.

Artigo recebido em: 08/03/2020

Artigo aprovado em: 24/04/2020

Artigo publicado em: 28/04/2020 